\title{
Protein-Induced Sequence Diversity of Z-DNA
}

\author{
Yang-Gyun Kima \\ Deparment of Chemistry, School of Natural Sciences. Sunghvunkw an Chiversity. Simion $+40-746$, Korea \\ E-mail: vgkimmitiâskku.edu \\ Received Januarv 29. 2007
}

Key Words : Z-DNA, Z $\alpha$. Circular dichroism. B-Z conversion, Sequence diversity

Right-handed B-DNA is a major form of double-stranded DNA (dsDNA) and used for the structural support of genetic information. It has been also known that DNA can form diverse shapes either in vivo or in vitro. Among them. lefthanded Z-DNA is one of the most well known non-B-DNA structures. Although the biological roles of Z-DNA in wino have been elusive despite of intense studies since its discovery decades ago. recent finding of Z-DNA binding motif. $Z \alpha$ provides a promising outlook to elucidate the relevance of $Z$-DNA in biological systems. The $Z \alpha$ was first identified from an RNA editing enzyme: human dsRNA adenosine deaminase 1 (hADARl) that has two $Z \alpha$-motifcontaining-domains. $Z \alpha_{A D A R 1}$ and $Z \beta_{A D A R 1}$ at the N-terminal region. ' Soon findings of several other proteins containing one or two $Z \alpha$ motifs have been followed. ${ }^{1-3}$ The $Z \alpha_{A D A R}$, the first $N$-terminal $Z \alpha$ domain from human ADAR1. has been used as a tool to investigate Z-DNA in vitro as well as in vivo. ${ }^{4-7}$ Its competent ability to specifically recognize $Z$-conformation of nucleic acids could broaden its further uses.

Z-DNA formation is favored alternating pyrimidinepurine (APP) sequences. The sequence consisted with alternating $\mathrm{dG}$ and $\mathrm{dC}$ is formed best in Z-conformation. ${ }^{8}$ However other sequences of dsDNAs can also adopt Z-

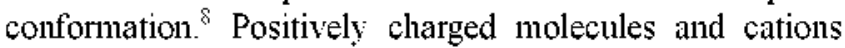
such as spermidine and cobalt hexamine can stabilize dsDNA in Z-conformation. \& Although APP sequences are known to be ideal to form Z-DNA. ont of alternating pyrimidine-purine (non-APP) sequences have been reported to form Z-DNA in a non-physiological condition. The Xcrystallographic study revealed that a short dsDNA with 5methyl dCs (m5dCs) substituting dCs in d(m5CGCCm5CG/ m5CGGGm5CG) could adopt Z-conformation when crystallized with magnesium and spermidine. ${ }^{\text {la }}$ Other biophysical studies have also shown that non-APP sequences can be accommodated by the left-handed structures in nonphy siological conditions. ${ }^{13-12}$

Ability to form Z-conformation in various DNA sequences has been assessed by Ho group using thermodynamic approaches. ${ }^{3}$ Based on the B-Z transition energy of all possible base-pairings determined by experimentally they developed the computer program named as 'ZHUNT" that can predict relative propensity for given DNA sequences to

"This work has been carried out at the Chung-Ang University and partly at Sungkyunkwan University. form Z-DNA: i.e., the higher Z-score means the easier to form $Z$-DNA in a given DNA sequence. It has been known that $Z \alpha_{A D A R 1}$ is a very strong $Z$-forming ligand to facilitate Z-DNA formation by binding and stabilizing double-stranded nucleic acids composed of APP sequences. ${ }^{1+18}$ Although APP sequences including $d(C G)$ repeats and $d(C A / T G)$ were subjects of studies for $Z \alpha_{A D A R} / Z-D N A$ interaction, the formation of Z-DNA is not restricted only to APP sequences. $^{19}$

Our approach to study the $Z \alpha_{\mathrm{ALAR}} / Z$-DNA interactions in diverse non-APP sequences of dsDNAs was based on Zscore as a guidance of Z-forming potential. ${ }^{13.19}$ DNA sequences for this study were chosen from a randomly selected region of the human genome (Accession number. AC113361.3). Their Z-scores determined by the ZHUNT program (available at http:/oregonstate.edu/dept/biochenv/ faculty/ho.html) are summarized in Table 1. In the physiological condition with low salt concentration $(10 \mathrm{mM}$ HEPES $\mathrm{pH} 7.4 .10 \mathrm{mM} \mathrm{NaCl}$ ). circular dichroism (CD) was employed to monitor $\mathrm{B}-\mathrm{Z}$ conversion of dsDNA oligomers in the presence of $Z \alpha_{A D} A R 1$. After 30 min incubation. $C D$ spectrum was taken and compared with that of DNA alone. i.e. B-conformation of DNA. The results shown in Figure 1 demonstrated that $Z \alpha_{A D} A R 1$ facilitated the conversion of dsDNA oligomers with high Z-score sequences (S1-S4)

Table 1. Sequences of dsDNA substrates used for B-Z conversion in this study

\begin{tabular}{clc}
\hline Name & \multicolumn{1}{c}{ Sequence } & Z-score \\
\hline S1 & 5'-GGACGCCCGGGCGCCCGC-3' & 2050 \\
& 3'-CCTGCGGGCCCGCGGGCG-5' & \\
S2 & 5'-CGGTGCGGCGCCC-3' & 1151 \\
& 3'-GCCACGCCGCGGG-5' & \\
S3 & 5'-GGCGCGCATGGCTGGGCGCGGG-3' & 1137 \\
& 3'-CCGCGCGTACCGACCCGCGCCC-5' & \\
S4 & 5'-CGCGCGCCGCCCGGGC-3' & 705.4 \\
& 3'-GCGCGCGGCGGGCCCG-5' & \\
SC & 5'AGACTCCCCAAGGCTGGG-3' & 0.444 \\
& 3'-CCCAGCCTTGGGGAGTCT-5' & \\
CGCG & 5'-CGCCCG-3' \\
& 3'-GCGGGC-5' & \\
& 5'-CGCGCG-3' & \\
& 3'-GCGCGC-5' \\
\hline
\end{tabular}

The d(CGCCCG:CGGGCG) sequence motifs are indicated by underlines. Z-scores of CGCCCG and CG3 were not determined because length of DNA must be at least 12 base pairs for calculation. 

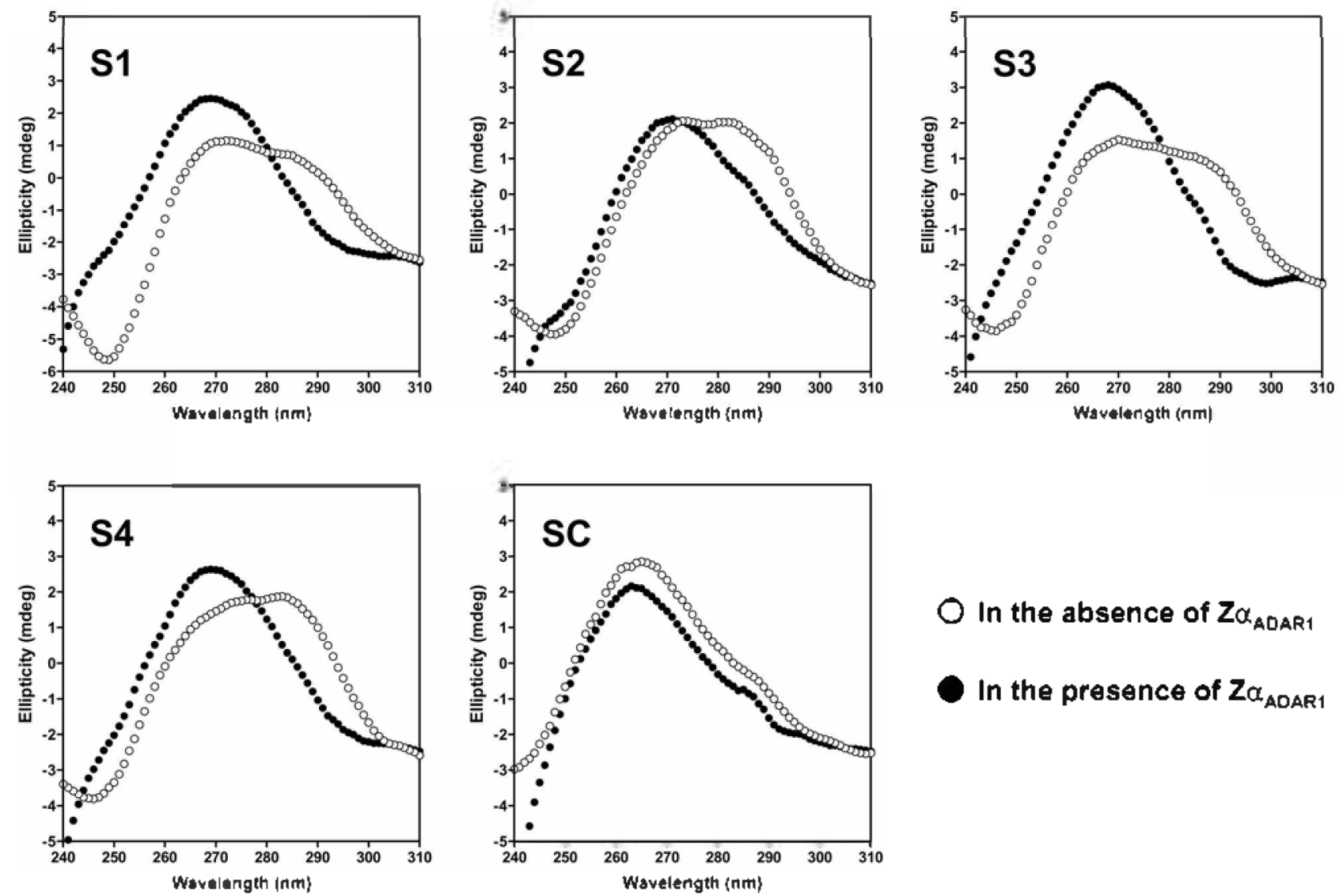

$O$ In the absence of $Z_{\alpha_{A D A R}}$

In the presence of $Z_{\alpha_{A D A R 1}}$

Figure 1. B-Z conversion of the various dsDNA substrates. CD spectra of reactions with different DNA substrates, $\mathrm{Sl}-\mathrm{S} 4$ and $\mathrm{SC}$, at $25^{\circ} \mathrm{C}$ were obtained before adding $Z \alpha_{\mathrm{ADARI}}$ (open circle) and in the presence of $Z \alpha_{\mathrm{A}}[\mathrm{ARI}$ (closed circle) after 30 min incubation, respectively: Spectral changes toward Z-DNA in high Z-score DNA samples (SI-S4) were observed after Z $\alpha_{A}[$ AkI was added, while the negative control, SC, did not show Z-DNA fomation in the presence of Z $\alpha_{A D A R I}$. Inversion of the CD spectrum around $255 \mathrm{~nm}$ and $292 \mathrm{~nm}$ is a typical characteristic of $B-Z$ conversion.

toward Z-conformation, while the negative control dsDNA (SC) with very low Z-score showed no significant Z-DNA formation in the same condition. In each DNA substrate. changes of $\mathrm{CD}$ spectra in B- and Z-confommations were somewhat different due to the different base compositions. However. all high Z-score dsDNAs showed typical inversed spectral changes between $250 \mathrm{~nm}$ and $300 \mathrm{~nm}$ increase at $255 \mathrm{~nm}$ and decrease at $292 \mathrm{~nm}$ when the $\mathrm{B}$ to $\mathrm{Z}$ conversion occurs -. which is an indicative of B-Z conversion in DNA. Overall. our result demonstrated that $Z \alpha_{A D A R}$ can also work as a powerful agent to generate $B-Z$ conversion in a variety of sequences containing non-APP sequences.

From the study of B-Z conversion of non-APP DNAs induced by $Z \alpha_{A D A R}$, we found that the $d(C G C C C G /$ CGGGCG) sequence motif was presented twice in SI. and once in S4 (underlined in Table 1), respectively. The Z-DNA structure of this non-APP DNA sequence containing 5ndCs substituting dCs was previously solved by X-ray crystal diffraction analysis. ${ }^{11}$ However, base modifications and positively charged ions used for the crystallization of $\mathrm{d}(\mathrm{CGCCCG} / \mathrm{CGGGCG})$ was a major driving force to stabilize this non-APP sequence into $Z$-confomation. Thus this study is unlikely to represent that $\mathrm{d}(\mathrm{CGCCCG} / \mathrm{CGGGCG})$ can form Z-DNA in physiological condition.
In our study. we used unmodified d(CGCCCG/CGGGCG) to test whether $Z \alpha_{3} \mathrm{DARl}$ can convert it into Z-DNA in physisiological condition or not. The CD experiments for $\mathrm{d}$ (CGCCCG/CGGGCG) together with $\mathrm{d}(\mathrm{CGCGCG)}$ ) as a positive control were carried out at $10^{\circ} \mathrm{C}$ because of their low melting temperature. $24^{\circ} \mathrm{C}$ for both. ${ }^{21} \mathrm{In}$ Figure $2 \mathrm{~A}$, the $C D$ spectra clearly showed that $Z \alpha_{\mathrm{AD} A \mathrm{AR} 1}$ can induce $Z$ conformation of d(CGCCCG/CGGGCG). In addition, the rates of $\mathrm{B}-\mathrm{Z}$ conversion for both DNAs were also monitored (Fig. 2B). $\mathrm{B}$ to $\mathrm{Z}$ conversion of $\mathrm{d}$ (CGCCCG/CGGGCG) by $\mathrm{Z} \alpha_{\mathrm{AL}) \mathrm{AR} 1}$ was faster than that of $\mathrm{d}(\mathrm{CGCGCG})_{2}$. This result was unexpected since thermodynamic stability of d(CGCG$\mathrm{CG})_{2}$ in Z-conformation is more stable than that of non-APP $\mathrm{d}$ (CGCCCG/CGGGCG). In fact. similar observation was previously reported when kinetics of $B$ to $Z$ conversion of various APP sequences by $Z \alpha_{A[2 A R]}$ was investigated. ${ }^{17}$ Again, our result suggests that the $B$ to $Z$ conversion by $Z \alpha_{A D \perp A R 1}$ may require a path depending on the kinetic aspect of DNA structural change.

In summary. we examined Z-DNA formation in diverse DNA sequences in the presence of $Z \alpha_{\mathrm{A} D \mathrm{AR}]}$. Our result clearly demonstrated that $Z \alpha_{A D A R}$ is capable of inducing $\mathrm{B}$ to $Z$ conversion of non-APP sequences, as well as APP sequences. In the previous studies non-APP sequences only 

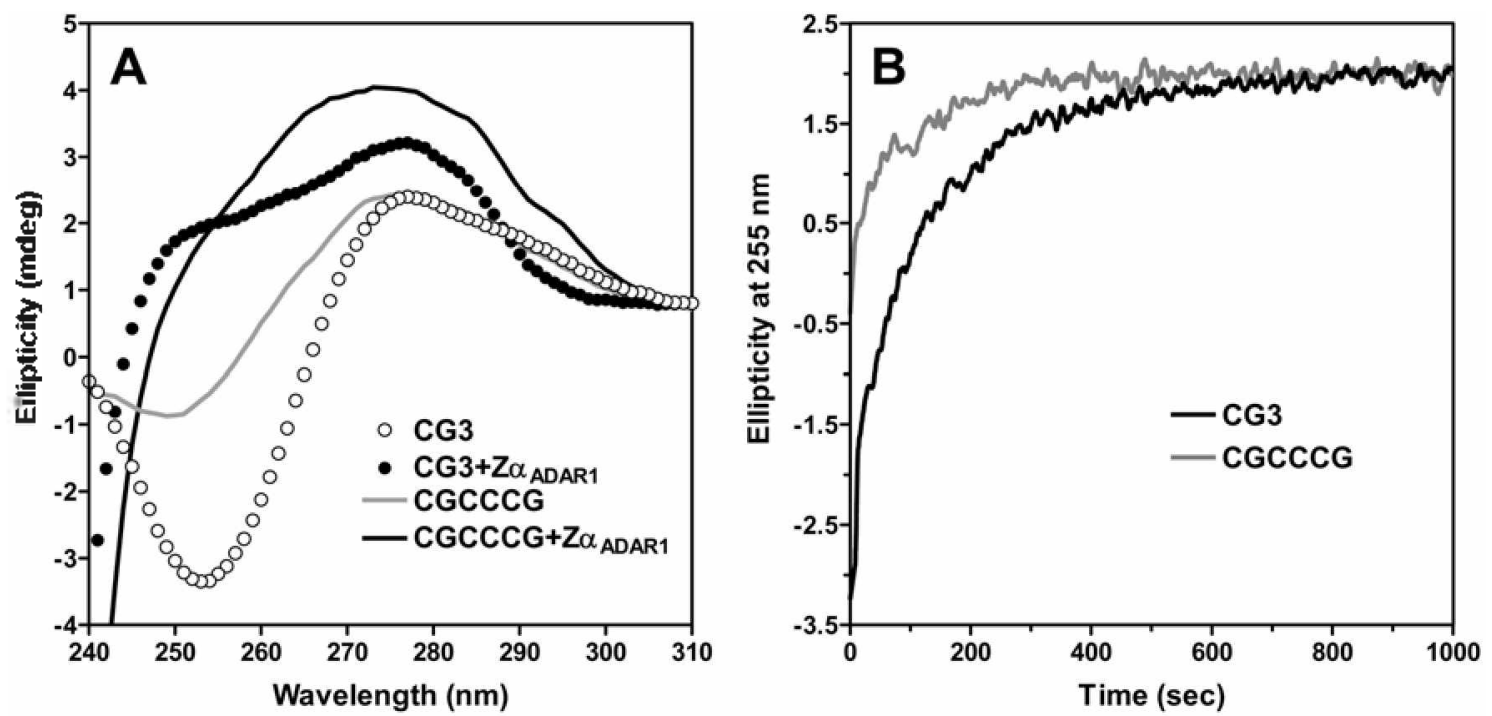

Figure 2. B-Z conversion and kinetic behavior of short dsDNA substrates induced by $Z \alpha_{A}[1 \mathrm{AR}]$. (A) CD spectral changes of short dsDNA substrates, CGCCCG (lines) and CG3 (circles), at $10^{\circ} \mathrm{C}$ were obtained before adding $Z \alpha_{A[A R]}$ (grey line or open circle) and in the presence of $Z \alpha_{A D A R I}$ (solid line or closed circle) after 30 minn incubation, respectively. (B) Time-dependent change at $255 \mathrm{~nm}$ in the CD spectrum was monitored to detemine rates of $\mathrm{B}-\mathrm{Z}$ conversion of $\mathrm{CG} 3$ (solid line) and CGCCCG (grey line ). The result showed that the B-Z conversion of CGCCCG is taster than $\mathrm{CG} 3$, which indicates that $Z \alpha_{\mathrm{ADAR}}$-induced B-Z conversion is not dependent on themodynamic stability of DNA in Z-confonmation.

formed in high salt concentration and with modified bases such as $\mathrm{m} 5 \mathrm{dCs}$ or $\mathrm{Br} 5 \mathrm{dCs}$. Our work here would be a proof for the potent ability of $Z \alpha_{A D A R I}$ that facilitates $Z$-DNA formation in various DNA sequences. Thus. the ability of $Z \alpha_{A D A R]}$ for inducing $Z$-conformation of a short dsDNA containing unmodified non-APP sequence is potentially useful for studies in physiological conditions. For instance. structural Study of non-APP sequences would be accelerated by using $Z \alpha_{A D A R I}$ in physiological conditions rather than by using modified bases and high salt concentration. In addition. $Z \alpha_{A D A R J}$ may become a powerful agent to facilitate $Z$-DNA formation in DNA nanostructures in the future.

\section{Experimental Procedures}

Protein purification and DNA preparation. The $Z \alpha_{A D A R]}$ domain (aa 133-aa 199) from hADARl was expressed and purified according to the previously described method with modification. ${ }^{21}$ Briefly, the coding region of the $Z \alpha_{A D A R I}$ domain from hADARI cloned in $\mathrm{pET} 28 \mathrm{a}$ vector (Novagen) was expressed with the $\mathrm{N}$-terminal His-tag in $E$. coll and purified by affinity purification using a metal chelation column (Amersham Biosciences). Thrombin digestion was then carried out to remove the N-terminal His-tag. The $Z \alpha_{A D A R]}$ protein was further purified to homogeneity with a Hi-Trap SP column (Amersham Biosciences). Finally the purified $Z \alpha_{A D A R 1}$ protein was dialyzed against buffer $\mathrm{A}$ ( 5 mM HEPES, $\mathrm{pH} 7.5 .10 \mathrm{mM} \mathrm{NaCl}$ ). and concentrated to above $1 \mathrm{mM}$.

DNA oligonucleotides were synthesized and purified by HPLC. DNAs were dissolved in buffer B (10 mM Tris-Cl. $\mathrm{pH} 7.4 .50 \mathrm{mM} \mathrm{NaCl}$. $0.1 \mathrm{mM}$ EDTA). Annealing for dsDNA substrates was carried out by mixing each equalmolar DNA oligonucleotide to $200 \mu \mathrm{g} / \mathrm{mL}$ in CD buffer ( $10 \mathrm{mM}$ HEPES, $\mathrm{pH} 7.4$. $10 \mathrm{mM} \mathrm{NaCl}, 0.1 \mathrm{mM}$ EDTA). heating for $5 \mathrm{~min}$ at $95^{\circ} \mathrm{C}$, and then cooling slowly to $25^{\circ} \mathrm{C}$. B-Z conversion of the dsDNA samples from each set of DNA oligonuclotides

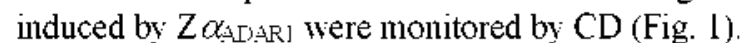

CD measurement. All measurements were taken on 40 $\mu \mathrm{g} / \mathrm{mL}$ of DNA ( $60 \mu \mathrm{M}$ in base pair) in CD buffer in a 0.2 $\mathrm{cm}$ quartz cell. $\mathrm{CD}$ spectra were taken at $25^{\circ} \mathrm{C}$ using an Jasco J810 CD spectrometer with the exception of the short DNA substrates $\left(10^{\circ} \mathrm{C}\right.$ for CGCCCG and CG3). Proteins were added to the sample in the final concentration of $30 \mu \mathrm{M}$ from a concentrated stock solution, not exceeding $5 \%$ of the total volume. After $30 \mathrm{~min}$ incubation. CD spectra of the reaction mixtures were then recorded between 240 nu to $310 \mathrm{~nm}$ at $1 \mathrm{~nm}$ intervals averaged over $3 \mathrm{sec}$. The $C D$ spectrum of the each dsDNAs incubated with $Z \alpha_{\mathrm{AI} / \mathrm{AR} 1}$ showed a typical Z-conformation of DNA, which confimed that $Z \alpha_{A[A R]}$ was capable of flipping various DNA sequences containing non-APP sequences into the Z-conformation. Time-dependent change of $C D$ spectrum at $255 \mathrm{~nm}$ was recorded at $1 \mathrm{sec}$ intervals for $30 \mathrm{~min}$. to measure the rate of $\mathrm{B}$ to $\mathrm{Z}$ conversion induced by $\mathrm{Z} \alpha_{\mathrm{ADAR}}$.

Acknowledgment. This Research was supported by the Chung-Ang University Research Grants in 2005.

\section{References}

1. Herbert. A.: Altken. I.: Kim. Y. G.: Mian1. I. S.: Nishikura. K.: Rich. A. Proc. Natl Acad Sci. LS. 1997. 94. 8421.

2. Fu. Y.: Comella. N.: Tognazzi. K.: Brown. L. F.: Drorak. H. F.: Kocher. O. Gene 1999. 240,157.

3. Rothenburg, S.: Deigendesch, N.; Dittmar, K; Koch-Nolte. F; Haag. F.: Lowenhaupt. K; Rich. A. Proc. Natl Acad. Sci. LS. 
2005. 102. 1602

4. Kim. Y. G.: Kim. P. S.: Herbert. A.: Rich. A. Proc. Natl Acad Soi. LS.A 1997, 94. 12875.

5. Kim, Y. G.: Lowenhaupt, K.; Schwartz. T; Rich, A. J. Biol. Chem. 1999, 27f, 19081.

6. Liu, R.: Lils. H. Chen, X.: Kirby: M.; Brown, P. O.: Zhao. K. Ce/l 2001. 106.309.

7. Liu. H.: Mulholland. N.: Fu. H.: Zhao. K. Mfol. Cell Biol. 2006. 26. 2550 .

8. Rich, A.: Nordheim, A.: Wang, A. H. 1984, 53.791.

9. Feigon. J.: Wang. A. H.: van der Marel G. A.: van Boonn, I. H.: Rich. A. Science 1985. 230.82.

10. Schroth. G. P.: Kagawa. T. F.: Ho. P. S. Biochentistry 1993. 32. 13381.

11. Wang. A. H.: Gessner. R. V: van der Marel. G. A.: van Boom. J. H.: Rich. A. Proc. Hatl foad Sci. LS. 1985. 82.3611

12. Eichman, B. F.: Schroth, G. P.: Basham, B. E.: Ho, P. S. Nicleic Acids Res. 1999, 27. 543

13. Ho. P. S.: Ellison. M. J.: Quigley G. J.: Rich. A. EM BO J. 1986. 5.
2737.

14. Berger. I.: Winston1. W.: Manoharan. R.: Schwartz. I:: Altken. J.: Kiml. Y. G.: Lowenhaupt. K.: Herbert. A.: Rich. A. Biochemistm 1998. 37,13313 .

15. Herbert, A.: Schade. M.: Lowenhaupt, K.: Alfken. J.: Schwartz. T.: Shlvalhtenko. L. S.; Lyubchenko, Y. L.; Rich. A. Nucleic Acids Res 1998. 26.3486.

16. Kiml. Y. G.: Lowenhaupt. K.: Maas. S.: Herbert. A.: Schwartz. T: Rich. A. J. Biol. Chem. 2000. 275. 26828.

17. Quyen, D. V; Kim, K. K; Kim. Y. G. Bull. Korean Chem. Soc. 2006. 27, 1071 .

18. Brown. B. A.. 2nd, Lowenhaupt. K.: Wilbert, C. M.: Hanlon, E. B.: Rich. A. Proc. Natl Acad Sci. USA 2000. 97. 13532.

19. Schroth. G. P.: Chou. P. J.: Ho. P. S. J. Biol Chem 1992. 267. 11846

20. Wallace. R. B.: Shaffer, J.: Murphy, R. F; Bonner. J.: Hirose, T:; Itakura, K. Nucleic Acids Res. 1979. 6, 3543

21. Schwartz, T; Lowenhaupt. K; Kim. Y. G.: Li, L.: Brown, B. A.. 211d: Herbert. A.: Rich. A. J. Biol. Chent. 1999. 274. 2899. 